\title{
PERANCANGAN ENTERPRISE ARCHITECTURE LAYANAN SPBE (E-GOVERNMENT) DI LINGKUNGAN PEMKAB SUKABUMI
}

\author{
Devita Wulandari ${ }^{1 *}$, Soni Fajar Surya Gumilang ${ }^{1}$, Rahmat Mulyana ${ }^{1}$ \\ ${ }^{1}$ Sistem Informasi, Universitas Telkom \\ email: *devitawulandari@student.telkomuniversity.ac.id
}

\begin{abstract}
To increase the Electronic-Based Government System (SPBE) maturity level and comply with Presidential Regulation no. 95 of 2018, the Sukabumi Regency Government needs to standardize the SPBE design to be implemented appropriately integrated with utilizing technological advances optimally. One of the frameworks used to design the SPBE architecture is using the Enterprise Architecture (EA). EA aims to meet the gap between the needs of stakeholders and the availability of government administration services. The journal's focus on the design of this SPBE EA is on the SPBE Service Domain in the Electronic-Based Government Administration Service. The design is carried out using a combination of references to the SPBE Presidential Regulation and the National SPBE Master Plan Attachment and one of the main components of the EA framework, namely TOGAF ADM. This design produces an output in the form of an Electronic-Based Government Administration Service Catalog. It is expected to be used as a reference in developing technology in the Regency Government Sukabumi both from practical contributions and academic contributions.
\end{abstract}

Keywords: Enterprise Architecture; Service Architecture; SPBE; TOGAF ADM

\begin{abstract}
Abstrak: Dalam rangka meningkatkan tingkat kematangan Sistem Pemerintah Berbasis Elektronik (SPBE) dan mematuhi Peraturan Presiden No. 95 Tahun 2018, Pemerintah Kabupaten Sukabumi perlu melakukan standarisasi terhadap perancangan SPBE agar dapat terimplementasi dan terintegrasi dengan baik dalam memanfaatkan kemajuan teknologi secara optimal. Salah satu kerangka kerja yang bisa digunakan untuk merancang Arsitektur SPBE yaitu menggunakan Enterprise Architecture (EA). EA bertujuan untuk memenuhi kesenjangan antara kebutuhan pemangku kepentingan dengan ketersediaan layanan administrasi pemerintahan. Fokus jurnal pada perancangan EA SPBE ini yaitu pada Domain Layanan SPBE di bagian Layanan Administrasi Pemerintahan Berbasis Elektronik. Perancangan yang dilakukan memanfaatkan kombinasi antara referensi pada Perpres SPBE dan Lampiran Rencana Induk SPBE Nasional serta salah satu komponen utama framework EA yaitu TOGAF ADM. Perancangan ini menghasilkan keluaran berupa Katalog Layanan Administrasi Pemerintahan Berbasis Elektronik dan diharapkan dapat dijadikan sebagai acuan dalam melakukan pengembangan teknologi di Pemkab. Sukabumi baik dari kontribusi praktis maupun kontribusi akademik.
\end{abstract}

Kata kunci: Arsitektur Layanan; Enterprise Architecture; SPBE; TOGAF ADM 
DOI: https://doi.org/10.33330/jurteksi.v8i1.1204

Available online at http://jurnal.stmikroyal.ac.id/index.php/jurteksi

\section{PENDAHULUAN}

Dengan pertumbuhan teknologi yang terus meningkat secara pesat membuat pemerintah di seluruh dunia berbondong-bondong dalam memanfaatkan penggunaan Sistem Pemerintahan Berbasis Elektronik ataupun E-Government. E-government adalah sistem teknologi informasi dan komunikasi (TIK) yang dimiliki atau dioperasikan oleh pemerintah untuk mendorong pemberdayaan masyarakat, meningkatkan penyampaian layanan, memperkuat akuntabilitas, dan meningkatkan transparansi dan efisiensi [1]. Salah satu tujuan dari E-Government yaitu untuk meningkatkan proses organisasi antarpemerintah dengan saling melakukan kerjasama dan koordinasi terhadap peraturan, kepatuhan, dan lain-lain [2]. Pada tahun 2020, United Nations (UN) $E$ Government Survey memberikan peringkat EGDI (E-Government Development Index) kepada Indonesia di peringkat 88 yang telah berhasil memasuki peringkat 100 besar dari 193 negara di dunia [3]. Hal ini merupakan suatu pencapaian yang meningkat jika dibandingkan dengan EGDI di tahun 2018 dimana Indonesia berada pada peringkat 107 [4]. Berdasarkan hasil survey tersebut, pemerintah Indonesia akan terus memantau secara berkala untuk menilai dan mengukur kematangan implementasi SPBE termasuk tahapan kapabilitas proses dan kapabilitas fungsi indeks, agar bisa menunjang pemerintahan digital dan pembangunan jangka panjang dalam memenangkan persaingan global [5][6].

Tidak hanya itu, salah satu upaya yang sudah dilakukan pemerintah Indonesia adalah dengan merumuskan Peraturan Presiden Nomor 95 tentang Sistem Pemerintahan Elektronik Tahun 2018. Peraturan tersebut bertujuan untuk mewujudkan pemerintahan yang bersih, efisien, transparan, akuntabel, dan andal, membutuhkan Sistem Pemerintahan Berbasis Elektronik secara nasional [7]. Pemerintah Kabupaten Sukabumi perlu melakukan standarisasi terhadap perancangan SPBE agar dapat terimplementasi dan terintegrasi dengan baik dalam memanfaatkan kemajuan teknologi secara optimal. Selain itu, diharapkan dengan adanya integrasi antar seluruh sistem dapat membentuk jaringan sistem manajemen dan proses kerja yang memungkinkan instansi-instansi pemerintah bekerja secara terpadu untuk menyederhanakan akses ke seluruh informasi dan pelayanan [8]. Salah satu kerangka kerja yang bisa digunakan untuk merancang SPBE yaitu menggunakan Enterprise Architecture. EA bertujuan untuk menjembatani kesenjangan komunikasi antara stakeholder dan Teknologi Informasi (TI), serta meningkatkan keselarasan bisnis dan TI [9]. Selain itu, EA juga dapat digunakan untuk menganalisis, merancang, merencanakan serta mengimplementasikan analisis agar berhasil melaksanakan strategi bisnis yang sesuai dengan kebutuhan Pemkab. Sukabumi [10]. Terdapat enam domain arsitektur SPBE yang bisa dirancang yaitu domain proses bisnis, data dan informasi, aplikasi, infrastruktur, keamanan dan layanan. Namun perancangan kali ini hanya difokuskan ke satu perancangan yaitu pada domain layanan SPBE. Perancangan yang dilakukan akan memanfaatkan kombinasi antara peraturan teknis Arsitektur SPBE serta salah satu komponen utama framework EA yaitu The Open Group Architecture Framework (TOGAF) Architecture Development Method (ADM). Arsitektur SPBE bertujuan untuk membuat kerangka dasar yang menggambarkan integrasi antara proses bisnis, data dan informasi, infra- 
struktur, aplikasi dan keamanan untuk menghasilkan Layanan SPBE yang terintegrasi[7]. Sementara TOGAF ADM merupakan pengembangan arsitektur dan sebuah metode berulang untuk mengelola cycle EA yang merupakan inti dari bentuk standar TOGAF [11] [12].

\section{METODE}

Tahapan yang dilakukan dalam melakukan perancangan Layanan Administrasi Pemerintahan Berbasis Elektronik dibagi menjadi 3 tahapan yaitu tahap inisiasi, tahap perancangan menggunakan 2 tahapan EA serta tahap kesimpulan dan saran yang dapat dilihat pada Gambar 1 .

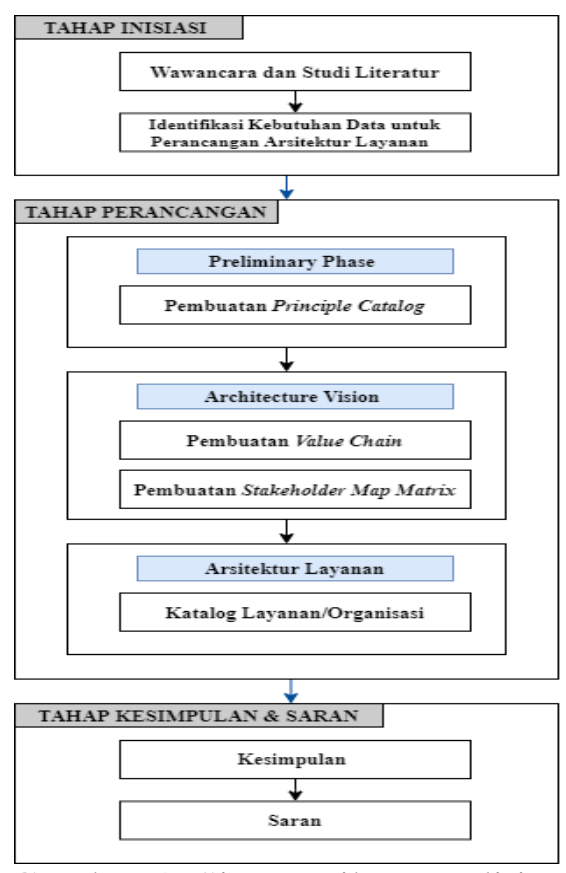

Gambar 1. Sistematika Penelitian

Tahap pertama dalam melakukan perancangan ini yaitu tahap inisiasi untuk mempersiapkan penelitian. Yang harus dilakukan pada tahap ini adalah mengenal dan mempelajari arsitektur perancangan SPBE serta melakukan identifikasi kebutuhan data terhadap objek penelitian untuk menemukan perma- salahan dan lingkup bisnis pada Pemkab. Sukabumi menggunakan metode wawancara dan studi literatur. Wawancara dilakukan dengan mengajukan pertanyaan terhadap stakeholder yang ada pada domain layanan Pemkab. Sukabumi untuk mendapatkan kondisi layanan saat ini yang ada di domain tersebut. Selain itu, studi literatur dibutuhkan untuk dijadikan acuan dalam merancang Arsitektur SPBE Pemkab. Sukabumi menggunakan Peraturan Presiden No. 95 Tahun 2018 dan dokumen RPJMD Kab. Sukabumi.

Tahap selanjutnya yaitu tahap perancangan dengan melakukan analisis serta perancangan artefak yang dibutuhkan sesuai dengan kebutuhan dari Pemkab. Sukabumi di domain layanan menggunakan framework EA yang terdiri dari 2 tahapan yaitu preliminary phase dan architecture vision. Tahap preliminary phase membahas prinsip-prinsip arsitektur layanan yang nantinya akan digunakan untuk mengembangkan enterprise architecture SPBE dalam jangka panjang. Tahap architecture vision akan menghasilkan value chain yang menggambarkan nilai-nilai yang dimiliki oleh Pemkab. Sukabumi yang dilihat berdasarkan aktivitas-aktivitas yang ada di dalam Pemkab tersebut. Lalu, terdapat stakeholder map matrix yang menjelaskan setiap stakeholder internal terkait kepentingan, posisi, serta dampak keputusan untuk layanan yang ada di dalam Pemkab. Sukabumi. Tahap terakhir adalah tahap Arsitektur Layanan, pada tahap ini akan dihasilkan katalog Layanan Administrasi Pemerintahan Berbasis Elektronik yang ditargetkan sesuai dengan kebutuhan Pemkab. Sukabumi berlandaskan pada sembilan fungsi utama yang sesuai dengan amanah Peraturan Presiden Nomor 95 Tahun 2018.

Tahap terakhir yaitu tahap kesimpulan dan saran, setelah melakukan 
analisis serta perancangan akan dilakukan rangkuman berdasarkan hasil penelitian sehingga dapat diberikan kesimpulan maupun saran terhadap perancangan yang diusulkan dan diharapkan dapat memaksimalkan implementasi perancangan arsitektur layanan administrasi pemerintahan berbasis elektronik agar bisa menjawab permasalahan yang ada sehingga dapat meningkatkan efektifitas dan efisiensi untuk kemajuan teknologi di Pemkab. Sukabumi.

\section{HASIL DAN PEMBAHASAN}

\section{Preliminary Phase}

Tahap ini dilakukan untuk persiapan proses perancangan enterprise architecture serta inisiasi kebutuhan apa saja dalam melakukan arsitektur target. Artefak yang dihasilkan pada tahap ini berupa principle catalog bertujuan untuk menggambarkan prinsip layanan yang ada pada suatu organisasi/perusahaan. Berikut merupakan tabel principle catalog pada Pemkab. Sukabumi.

Tabel 1. Principle Catalog

\begin{tabular}{lll}
\hline No & Arsitektur & Prinsip \\
\hline \multirow{3}{*}{1} & Layanan & Sederhana \\
\cline { 3 - 3 } & & Partisipatif \\
& & Akuntabel \\
& & Berkelanjutan \\
& & Transparansi \\
\hline
\end{tabular}

Berdasarkan Tabel 1, arsitektur layanan memiliki enam prinsip meliputi kesederhanaan yaitu layanan mudah dipahami dan dilaksanakan, partisipatif yaitu penataan layanan harus melibatkan masyarakat atau pihak lain, akuntabel yaitu kegiatan yang dilakukan harus bertanggung jawab kepada pemangku kepentingan terkait, keberlanjutan berarti kegiatan harus terus ditingkatkan, transparansi yaitu pelayanan yang diperoleh harus dapat diakses oleh masyarakat, dan keadilan dimana pelayanan dapat menjangkau seluruh masyarakat.

\section{Architecture Vision}

Tahap ini dilakukan untuk mendeskripsikan perancangan enterprise architecture agar mencapai tujuan utama organisasi, dan untuk menentukan ruang lingkup objek penelitian/stakeholder objek penelitian yang terfokus pada Pemkab. Sukabumi. Artefak yang dihasilkan pada tahap ini berupa value chain dan stakeholder map matrix.

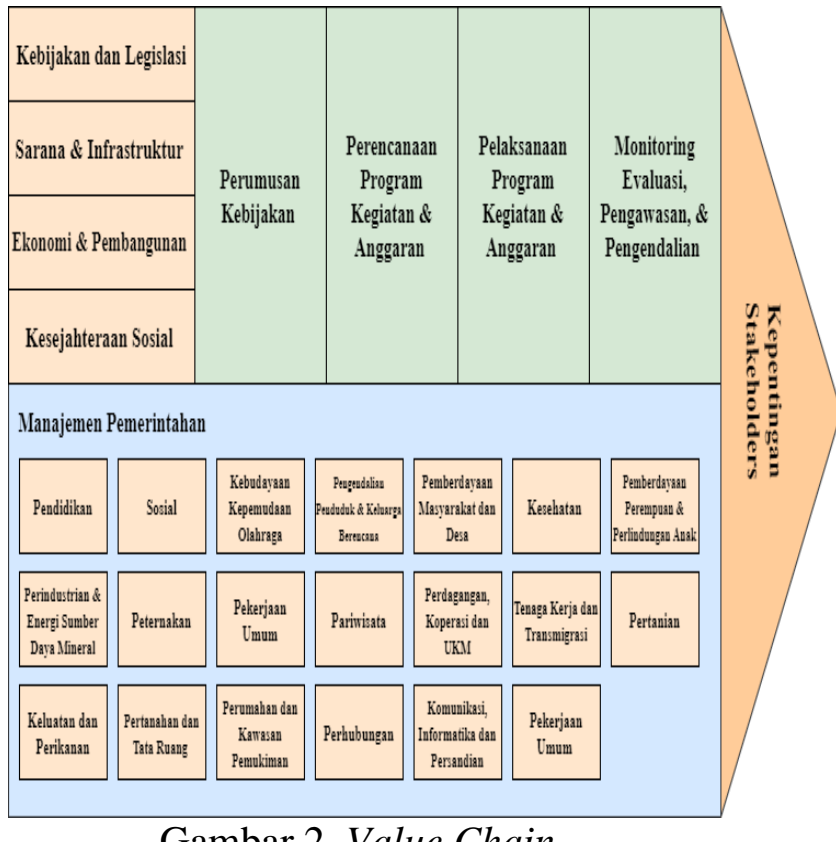

Gambar 2. Value Chain

Pada Gambar 2 menjelaskan aktivitas utama yang berisi manajemen pemerintahan atau seluruh dinas terkait pada Pemkab Sukabumi dimana nantinya akan saling terintegrasi dalam memanfaatkan layanan yang disediakan. Lalu terdapat aktivitas pendukung yang menjelaskan tentang hal-hal apa saja yang terlibat dalam mendukung seluruh dinas terkait. 
DOI: https://doi.org/10.33330/jurteksi.v8i1.1204

Available online at http://jurnal.stmikroyal.ac.id/index.php/jurteksi

Tabel 2. Stakeholder Map Matrix

\begin{tabular}{|c|c|c|}
\hline Stakeholder & Key Concern & Class \\
\hline $\begin{array}{l}\text { Sekretariat } \\
\text { Daerah }\end{array}$ & $\begin{array}{l}\text { Bertanggung jawab } \\
\text { dalam penyeleng- } \\
\text { garaan pelayanan } \\
\text { publik daerah. }\end{array}$ & $\begin{array}{l}\text { Key } \\
\text { Player }\end{array}$ \\
\hline $\begin{array}{l}\text { Dinas } \\
\text { Komunikasi, } \\
\text { Informatika } \\
\text { dan Persan- } \\
\text { dian }\end{array}$ & $\begin{array}{l}\text { Bertanggung jawab } \\
\text { terhadap penyusu- } \\
\text { nan dan pelaksanaan } \\
\text { kebijakan di bidang } \\
\text { komunikasi, in- } \\
\text { formatika dan statis- } \\
\text { tik persandian, } \\
\text { pengelolaan e- } \\
\text { government daerah. }\end{array}$ & $\begin{array}{l}\text { Keep } \\
\text { In- } \\
\text { formed }\end{array}$ \\
\hline $\begin{array}{l}\text { Badan } \\
\text { Perencana } \\
\text { an Pem- } \\
\text { bangunan, } \\
\text { Penelitian } \\
\text { dan } \\
\text { Pengem- } \\
\text { bangan Dae- } \\
\text { rah }\end{array}$ & $\begin{array}{l}\text { Bertanggung jawab } \\
\text { terhadap penyusu- } \\
\text { nan kebijakan teknis } \\
\text { \& pelaksanaan tugas } \\
\text { dukungan teknis di } \\
\text { bidang perencanaan } \\
\text { pembangunan, } \\
\text { penelitian dan } \\
\text { pengembangan, ser- } \\
\text { ta pembinaan ad- } \\
\text { ministrasi di ling- } \\
\text { kungan Badan. }\end{array}$ & $\begin{array}{l}\text { Keep } \\
\text { In- } \\
\text { formed }\end{array}$ \\
\hline $\begin{array}{l}\text { Badan } \\
\text { Pengelolaan } \\
\text { Keuangan } \\
\text { dan Aset } \\
\text { Daerah }\end{array}$ & $\begin{array}{l}\text { Bertanggung jawab } \\
\text { terhadap penyusu- } \\
\text { nan kebijakan teknis } \\
\text { khususnya di bidang } \\
\text { pengelolaan dan } \\
\text { keuangan aset dae- } \\
\text { rah, serta pelaksa- } \\
\text { naan kebijakan dae- } \\
\text { rah di bidang Ang- } \\
\text { garan, bidang } \\
\text { Akuntansi, bidang } \\
\text { Perbendaharaan dan } \\
\text { bidang Aset. }\end{array}$ & $\begin{array}{l}\text { Keep } \\
\text { In- } \\
\text { formed }\end{array}$ \\
\hline $\begin{array}{l}\text { Badan } \\
\text { Kepegawaian } \\
\text { dan Pengem- } \\
\text { bangan SDM }\end{array}$ & $\begin{array}{l}\text { Bertanggung jawab } \\
\text { terhadap penyusunan } \\
\text { rencana program kerja, } \\
\text { penyusunan dan pe- } \\
\text { rumusan kebijakan di } \\
\text { bidang Kepegawaian } \\
\text { dan Pengembangan } \\
\text { SDM. }\end{array}$ & $\begin{array}{l}\text { Keep } \\
\text { In- } \\
\text { formed }\end{array}$ \\
\hline
\end{tabular}

Tabel 2 menjelaskan tentang keterlibatan beberapa stakeholder khususnya pada Layanan Administrasi Pemerintahan terhadap kepentingan, posisi, serta dampak keputusan di dalam Pemkab. Sukabumi.

\section{Arsitektur Layanan}

Tahap ini merupakan salah satu output yang dihasilkan oleh satu atau lebih fungsi aplikasi SPBE yang bernilai manfaat. Layanan Administrasi Pemerintahan Berbasis Elektronik sendiri merupakan layanan yang akan mendukung manajemen birokrasi untuk meningkatkan kinerja pemerintahan pada Instansi Pusat dan Pemkab. Sukabumi. Terdapat 23 layanan yang disediakan dengan cara mengelompokkan kebutuhan enam fungsi utama yaitu perencanaan, penganggaran, keuangan, pengadaan barang dan jasa, kepegawaian dan kearsipan dengan aplikasi-aplikasi yang telah disediakan oleh Instansi Pusat ataupun Pemkab. Sukabumi. Selain itu, terdapat penyedia layanan yang disesuaikan berdasarkan hasil analisa terhadap penyedia aplikasi pendukung beserta pengguna layanan. Berikut merupakan tabel-tabel Katalog Layanan Administrasi Pemerintahan Berbasis Elektronik yang dibagi menjadi lima tabel berdasarkan fungsi masing-masing serta menjelaskan tentang siapa saja pengguna layanan yang akan memanfaatkan layanan yang telah disediakan di setiap fungsi pada Pemkab. Sukabumi. Layanan tersebut didukung oleh aplikasi yang telah disediakan oleh penyedia layanan baik dari Instansi Pusat maupun dari Pemkab. Sukabumi. 
DOI: https://doi.org/10.33330/jurteksi.v8i1.1204

Available online at http://jurnal.stmikroyal.ac.id/index.php/jurteksi

Tabel 3. Katalog Layanan Administrasi Pemerintahan Berbasis Elektronik Fungsi Perencanaan

\begin{tabular}{|c|c|c|c|c|}
\hline Fungsi & Layanan & $\begin{array}{l}\text { Aplikasi } \\
\text { Pendukung }\end{array}$ & Penyedia Layanan & $\begin{array}{l}\text { Pengguna } \\
\text { Layanan }\end{array}$ \\
\hline \multirow[t]{2}{*}{$\begin{array}{l}\text { Peren- } \\
\text { canaan }\end{array}$} & Layanan Perencanaan & 4 Aplikasi & $\begin{array}{ll}* \text { BAPPEDA } \\
\text { Kementerian Keu- } \\
\text { angan } \\
\text { BPPKAD } \\
\text { Kementerian Da- } \\
\text { lam Negeri }\end{array}$ & BAPPEDA \\
\hline & $\begin{array}{l}\text { Layanan Pengelolaan } \\
\text { Pengajuan } \\
\text { Perencanaan Ang- } \\
\text { garan }\end{array}$ & 1 Aplikasi & $\begin{array}{l}\text { Dinas Komu- } \\
\text { nikasi, Informatika } \\
\text { dan Persandian }\end{array}$ & BAPPEDA \\
\hline
\end{tabular}

Tabel 4. Katalog Layanan Administrasi Pemerintahan Berbasis Elektronik Fungsi Penganggaran dan Keuangan

\begin{tabular}{|c|c|c|c|c|}
\hline Fungsi & Layanan & $\begin{array}{l}\text { Aplikasi } \\
\text { Pendukung }\end{array}$ & Penyedia Layanan & $\begin{array}{l}\text { Pengguna } \\
\text { Layanan }\end{array}$ \\
\hline \multirow{4}{*}{$\begin{array}{l}\text { Pengang } \\
\text { garan }\end{array}$} & $\begin{array}{l}\text { Layanan Pengang- } \\
\text { garan }\end{array}$ & 3 Aplikasi & $\begin{array}{l}\text { Kementerian Keu- } \\
\text { angan }\end{array}$ & BPKAD \\
\hline & & & * BAPPEDA & \\
\hline & & & $\begin{array}{l}\text { Kementerian Da- } \\
\text { lam Negeri }\end{array}$ & \\
\hline & $\begin{array}{l}\text { Layanan Aplikasi } \\
\text { Penyusunan Doku- } \\
\text { men Anggaran }\end{array}$ & 1 Aplikasi & Internal & BPKAD \\
\hline $\begin{array}{l}\text { Keu- } \\
\text { angan }\end{array}$ & Layanan Keuangan & 3 Aplikasi & $\begin{array}{l}\text { Kemendagri } \\
\text { BPPKAD } \\
\text { Kementerian Da- } \\
\text { lam Negeri }\end{array}$ & BPKAD \\
\hline
\end{tabular}

Tabel 5. Katalog Layanan Administrasi Pemerintahan Berbasis Elektronik Fungsi Pengadaan

\begin{tabular}{|c|c|c|c|c|}
\hline Fungsi & Layanan & $\begin{array}{l}\text { Aplikasi } \\
\text { Pendukung }\end{array}$ & Penyedia Layanan & $\begin{array}{l}\text { Pengguna } \\
\text { Layanan }\end{array}$ \\
\hline \multirow{4}{*}{$\begin{array}{l}\text { Penga- } \\
\text { daan }\end{array}$} & $\begin{array}{l}\text { Layanan Pengadaan } \\
\text { Secara } \\
\text { Elektronik }\end{array}$ & 1 Aplikasi & * LKPP & $\begin{array}{l}\text { Bag. Pengadaan Ba- } \\
\text { rang dan Jasa - } \\
\text { Sekretariat Daerah }\end{array}$ \\
\hline & $\begin{array}{l}\text { Layanan Perencanaan } \\
\text { Umum dan Pengadaan }\end{array}$ & 1 Aplikasi & * LKPP & $\begin{array}{l}\text { Bag. Pengadaan Ba- } \\
\text { rang dan Jasa - } \\
\text { Sekretariat Daerah }\end{array}$ \\
\hline & $\begin{array}{l}\text { Layanan Pengelolaan } \\
\text { Katalog } \\
\text { Barang dan Jasa untuk } \\
\text { Pengadaan } \\
\end{array}$ & 1 Aplikasi & LKPP & $\begin{array}{l}\text { Bag. Pengadaan Ba- } \\
\text { rang dan Jasa - } \\
\text { Sekretariat Daerah }\end{array}$ \\
\hline & $\begin{array}{l}\text { Layanan Konsultasi } \\
\text { Online } \\
\text { Pengadaan Barang dan } \\
\text { Jasa }\end{array}$ & 1 Aplikasi & * SETDA & $\begin{array}{l}\text { Bag. Pengadaan Ba- } \\
\text { rang dan Jasa - } \\
\text { Sekretariat Daerah }\end{array}$ \\
\hline
\end{tabular}


DOI: https://doi.org/10.33330/jurteksi.v8i1.1204

Available online at http://jurnal.stmikroyal.ac.id/index.php/jurteksi

Tabel 6. Katalog Layanan Administrasi Pemerintahan Berbasis Elektronik Fungsi Kepegawaian

\begin{tabular}{|c|c|c|c|c|}
\hline Fungsi & Layanan & $\begin{array}{l}\text { Aplikasi } \\
\text { Pendukung }\end{array}$ & Penyedia Layanan & $\begin{array}{l}\text { Pengguna } \\
\text { Layanan }\end{array}$ \\
\hline \multirow{5}{*}{$\begin{array}{l}\text { Kepeg- } \\
\text { awaian }\end{array}$} & $\begin{array}{l}\text { Layanan Pengelolaan } \\
\text { Data dan Administra- } \\
\text { si Kepegawaian }\end{array}$ & 1 Aplikasi & BKPSDM & BKPSDM \\
\hline & $\begin{array}{l}\text { Layanan Absensi } \\
\text { Pegawai }\end{array}$ & 1 Aplikasi & * BKPSDM & BPKSDM \\
\hline & $\begin{array}{l}\text { Layanan Pengelolaan } \\
\text { Tunjangan Kinerja } \\
\text { ASN }\end{array}$ & 1 Aplikasi & BKPSDM & BKPSDM \\
\hline & $\begin{array}{l}\text { Layanan Pengelolaan } \\
\text { Formasi Pegawai }\end{array}$ & 1 Aplikasi & Kemenpan-RB & BKPSDM \\
\hline & $\begin{array}{l}\text { Layanan Pembelaja- } \\
\text { ran Online ASN }\end{array}$ & 1 Aplikasi & $\begin{array}{l}\text { BKPSDM } \\
\text { Diskominfo }\end{array}$ & BKPSDM \\
\hline
\end{tabular}

Tabel 7. Katalog Layanan Administrasi Pemerintahan Berbasis Elektronik Fungsi Pengelolaan Naskah Dinas dan Kearsipan

\begin{tabular}{|c|c|c|c|c|}
\hline Fungsi & Layanan & $\begin{array}{l}\text { Aplikasi } \\
\text { Pendukung }\end{array}$ & Penyedia Layanan & $\begin{array}{l}\text { Pengguna } \\
\text { Layanan }\end{array}$ \\
\hline \multirow{2}{*}{$\begin{array}{l}\text { Pengel- } \\
\text { olaan } \\
\text { Naskah } \\
\text { Dinas } \\
\text { dan } \\
\text { Kearsi- } \\
\text { pan }\end{array}$} & $\begin{array}{l}\text { Layanan Pengelolaan } \\
\text { Naskah } \\
\text { Dinas }\end{array}$ & 4 Aplikasi & $\begin{array}{l}\text { Diskominfosan } \\
\text { Kementerian } \\
\text { PAN-RB } \\
* \text { ANRI }\end{array}$ & $\begin{array}{l}\text { Dinas Kearsipan } \\
\text { dan Perpustakaan }\end{array}$ \\
\hline & $\begin{array}{l}\text { Layanan Penyim- } \\
\text { panan Arsip } \\
\text { dan Dokumen El- } \\
\text { ektronik }\end{array}$ & 1 Aplikasi & ANRI & DKIP \\
\hline
\end{tabular}

\section{SIMPULAN}

Penelitian ini menghasilkan katalog layanan administrasi pemerintahan berbasis elektronik yang ada di Pemkab. Sukabumi untuk mematuhi amanah Peraturan Presiden Nomor 95 Tahun 2018 mengenai Sistem Pemerintahan Berbasis Elektronik. Perancangan ini menggunakan framework Arsitektur SPBE yang dibantu dengan penggunaan framework EA yaitu TOGAF ADM dikarenakan peraturan teknis untuk Arsitektur SPBE masih dalam tahap penyusunan, sehingga referensi yang digunakan terbatas di Perpres dan Lampiran Rencana Induk SPBE. Penelitian ini digunakan untuk menghasilkan referensi arsitektur bagi pengembangan SPBE Pemkab. Sukabumi untuk lima tahun ke depan dari segi kontribusi praktis sekaligus digunakan untuk menyediakan studi kasus perancangan Arsitektur Layanan SPBE berbasis EA pada tingkat kota/kabupaten dari segi kontribusi akademik. Diharapkan dengan adanya rancangan ini akan bisa terus dikembangkan oleh Pemkab. Sukabumi khu- 
DOI: https://doi.org/10.33330/jurteksi.v8i1.1204

Available online at http://jurnal.stmikroyal.ac.id/index.php/jurteksi

susnya dalam pemanfaatan layanan.

\section{DAFTAR PUSTAKA}

[1] V. D. Ndou, "E - Government for Developing Countries: Opportunities and Challenges," Electron. J. Inf. Syst. Dev. Ctries., vol. 18, no. 1, pp. 1-24, 2004, doi: 10.1002/j.16814835.2004.tb00117.x.

[2] M. Alshehri and S. Drew, "EGovernment Fundamentals," Proc. IADIS Int. Conf. ICT, Soc. Hum. Beings 2010, 2010.

[3] United Nations, E-Government Survey 2020 - Digital Government in the Decade of Action for Sustainable Development: With addendum on COVID-19 Response, vol. 1, no. 1. 2020.

[4] United Nations, "E-Government Survey 2018: Gearing EGovernment to support transformation towards sustainable and resilient societies," New York, p. 270, 2018, [Online]. Available: https://publicadministration.un.org/e govkb/Portals/egovkb/Documents/un /2018-Survey/E-Government Survey 2018_FINAL for web.pdf.

[5] Republik Indonesia Goverment, "Regulation of the Minister of State Apparatus Empowerment and Bureaucratic Reform of the Republic of Indonesia Number 59 of 2020," Pemerintah Republik Indones., vol. 53, no. 9, pp. 1689-1699, 2020.
[6] Kemenpan/RB, "Laporan Kinerja Kementerian Pendayagunaan Aparatur Negara dan Reformasi Birokrasi Tahun 2019," p. 110, 2019.

[7] Pemerintah Indonesia, "Peraturan Presiden Republik Indonesia Nomor 95 Tahun 2018 tentang Sistem Pemerintahan Berbasis Elektronik," Menteri Huk. Dan Hak Asasi Mns. Republik Indones., p. 110, 2020.

[8] P. D. K. Sukabumi, RPJMD Kab. Sukabumi 2021 - 2026. 2021.

[9] S. Kotusev, "Enterprise architecture and enterprise architecture artifacts: Questioning the old concept in light of new findings," J. Inf. Technol., vol. 34, no. 2, pp. 102-128, 2019, doi: 10.1177/0268396218816273.

[10] Y. Gong and M. Janssen, "The value of and myths about enterprise architecture," Int. J. Inf. Manage., vol. 46, no. November 2018, pp. 19, 2019, doi: 10.1016/j.ijinfomgt.2018.11.006.

[11] The Open Group, "The TOGAF Standard, Version 9.2," TOGAF Libr., p. 504, 2018, [Online]. Available:

http://pubs.opengroup.org/architectu re/togaf9-doc/arch/.

[12] C. Kearny, A. Gerber, and A. Van Der Merwe, "Data-driven enterprise architecture and the TOGAF ADM phases," 2016 IEEE Int. Conf. Syst. Man, Cybern. SMC 2016 - Conf. Proc., pp. 4603-4608, 2017, doi: 10.1109/SMC.2016.7844957. 